\title{
Immune system dysfunction and malnutrition in hemodialysis patients part I - risk factors
}

\author{
Barbara-Joanna Bałan ${ }^{1}$, Anna Kaczorek ${ }^{2}$, and Marta Stelmasiak ${ }^{3}$ \\ ${ }^{1}$ Medical University of Warsaw \\ ${ }^{2}$ Warszawski Uniwersytet Medyczny \\ ${ }^{3}$ Kazimierz Pulaski University of Technology and Humanities in Radom
}

July 9, 2020

\begin{abstract}
The main causes of death in hemodialysis patients (HD) are cardiovascular diseases (CVD) and infections both of which are linked to impaired immune function. In patients with end stage renal disease, immunodeficiency and immune activation co-exist. Changes in the immune system are complex, but to some extent result from malnutrition or insufficiency in essential vitamins or trace elements. Based on the link between high mortality, immune system dysregulation, vitamins and trace elements insufficiency, it emphasizes the potential role of nutritional counseling and supplementation.
\end{abstract}

\section{Hosted file}

Immune system dysfunction and malnutrition in hemodialysis patients part I 07072020.pdf available at https://authorea.com/users/341293/articles/468239-immune-system-dysfunctionand-malnutrition-in-hemodialysis-patients-part-i-risk-factors 